\title{
MicroRNA-26a involved in Toll-like receptor 9-mediated lung cancer growth and migration
}

\author{
DE-SHENG JIANG, YU-WEI WANG, JING JIANG, SHU-MENG LI, SHUN-ZHI LIANG and HONG-YAN FANG \\ Department of Respiratory Medicine, The 454 Hospital of PLA, Nanjing, Jiangsu 210002, P.R. China
}

Received December 10,2013; Accepted April 8, 2014

DOI: $10.3892 /$ ijmm.2014.1764

\begin{abstract}
Toll-like receptor 9 (TLR9) has been shown to have a significant role in cancer. MicroRNAs (miRNAs), a group of small non-coding RNAs that fine tune translation of multiple target mRNAs, are involved in the development and progression of human cancers. The present study was undertaken to determine the roles of TLR9 on lung cancer and whether miR-26a is involved in TLR9-mediated lung cancer growth and migration. The lung cancer models were elicited by injecting human lung cancer cells into the left ventricle. The expression of TLR9 and miR-26a in lung cancer tissues obtained from lung cancer patients was increased. TLR9 ligand CpG-oligodeoxynucleotides (CpGODN) caused an increase in the mean tumor weight and the size of tumor mass in nude mice, and the proliferation and migration of $\mathrm{H} 460$ human lung cancer cells. CpG-ODN also induced an increase in the expression of miR-26a in H460 cells. The overexpression of miR-26a increased the weight and size of the tumor mass in the nude mice, and the proliferation and migration of $\mathrm{H} 460$ cells. Expression of phosphoinositide 3 kinase $(\mathrm{PI} 3 \mathrm{~K})$ and phosphorylation of protein kinase $\mathrm{B}(\mathrm{Akt})$ was increased after miR-26a overexpression in the H460 cells. PI3K inhibitor wortmannin (WM) or Akt inhibitor triciribine hydrate (TCN) eliminated the increase in the proliferation and migration induced by the overexpression of miR-26a in $\mathrm{H} 460$ cells. These results suggested that miR-26a is involved in the TLR9-mediated growth and migration of lung cancer through the PI3K-Akt signaling pathway.
\end{abstract}

\section{Introduction}

Toll-like receptors (TLRs) belong to a class of innate immune receptors that detect and clear invading microbial pathogens (1). Thirteen TLRs have been identified in mammals since 1997. TLR1, TLR2, TLR4, TLR5, TLR6, TLR10 and TLR11 are expressed on the cell surface, whereas TLR3, TLR7,

Correspondence to: Dr De-Sheng Jiang, Department of Respiratory Medicine, The 454 Hospital of PLA, 1 Malu Street, Nanjing, Jiangsu 210002, P.R. China

E-mail: jiangds1964@163.com

Key words: Toll-like receptor 9, microRNA-26a, lung cancer, proliferation, migration
TLR8 and TLR9 are expressed intracellularly on endosomal membranes (2). TLR11-13 are present in mice but lost from the human genome. The role of TLRs in tumor angiogenesis is diverse. It has been demonstrated that Helicobacter pylori, associated with gastric cancer, acts through TLR2 and TLR9 contributing to cancer cell invasion and angiogenesis (3). An association between TLR3, TLR4 and TLR9 expression and tumor aggressiveness and poor prognosis was identified in hepatocellular carcinoma (4). Findings of a meta-analysis showed that polymorphisms in TLR9 may play a role in cancer development (5). Human lung cancer cells have been shown to express functional TLR9 molecules (6,7). TLR9 expression in mononuclear cells was associated with an angiogenic phenotype and promoted lung cancer progression (8). TLR9 agonist also promoted the growth of human lung cancer cells (9). However, the mechanism involved concerning the association of TLR9 with lung cancer has yet to be elucidated.

MicroRNAs (miRNAs or miRs) are endogenous small non-coding RNAs of 21-25 nt in length (10), first discovered in Caenorhabditis elegans (11), that exert biological functions by post-transcriptional regulation of gene expression in a sequence-specific manner (12). Over 1,000 miRNAs have been identified in the human genome, and over one-third of all human protein coding genes are potentially regulated by miRNAs (13). miRNAs regulate the expression of genes involved in development, proliferation and growth (14-16). However, whether miRNAs are involved in the effects of TLR9 signaling on lung cancer cells remains to be elucidated.

Findings of recent studies have shown that miR-26a, a unique member of miRNAs, is involved in the progression of cancer. Expression of miR-26a in glioma cells significantly increased the growth rate and colony formation in vitro and tumor growth and angiogenesis in vivo, while a reduced expression of miR-26a played the opposite roles (17). Overexpression of miR-26a increased the proliferation of cholangiocarcinoma cells and colony formation in vitro, whereas miR-26 depletion reduced these parameters. In severe combined immune-deficient mice, overexpression of miR-26a in cholangiocarcinoma cells increased tumor growth (18). However, the possible role of miR-26a in TLR9 cancer growth and progression remains largely unknown.

The present study was designed to determine the roles of TLR9 on lung cancer and whether miR-26a is involved in the TLR9-mediated lung cancer growth and migration and the downstream signaling pathway. 


\section{Materials and methods}

Tissue samples. Fresh lung cancer and corresponding normal lung tissue samples (>10 cm away from the edge of the lung cancer) were obtained from lung cancer patients, and then snap-frozen in liquid nitrogen immediately after resection and kept at $-80^{\circ} \mathrm{C}$ until use. No patients had received chemotherapy or radiotherapy prior to surgery.

Animals and xenograft model. Animal experiments were performed using female nude mice (6- to 7-week-old) purchased from the Chinese Academy of Medical Sciences Laboratory Animal Center. The animals were housed in a temperature- and humidity-controlled room with a 12-h on-off light cycle and given free access to food and water. To establish the xenograft murine model, nude mice were anesthetized by intraperitoneal injection of ketamine $(100 \mathrm{mg} / \mathrm{kg})$ and xylazine $(10 \mathrm{mg} / \mathrm{kg})$ prior to intracardiac injections and were placed in the supine position. With a 25 -gauge needle, $\mathrm{H} 460$ cells $\left(2-3 \times 10^{5}\right)$ were injected into the left ventricle $(0.1 \mathrm{ml})$ after visualization of arterial blood flow into the syringe. After injection, the mice were placed on heating cages to recover from anesthesia. Tumor size was calculated as length $\mathrm{x}$ width $\mathrm{x}$ depth $\mathrm{x} 0.5236$ (19).

Cell line and culture. $\mathrm{H} 460$ human lung cancer cell line was purchased from American Type Culture Collection (Manassas, VA, USA) and cultured in RPMI-1640 with $10 \%$ fetal bovine serum $(\mathrm{FBS})$, penicillin $(100 \mathrm{IU} / \mathrm{ml}) /$ streptomycin $(100 \mu \mathrm{g} /$ $\mathrm{ml})$ at $37^{\circ} \mathrm{C}$ in a humidified $5 \% \mathrm{CO}_{2}$ incubator. The cells were subcultured every 3-5 days to maintain logarithmic growth until a sufficient number of cells $\left(5 \times 10^{7}\right.$ cells $\left./ \mathrm{ml}\right)$ was obtained for transfer to nude mice.

Adenovirus infection. Cells were plated in DMEM/Ham F12 with $10 \%$ FCS, at a density of $0.5-1 \times 10^{5}$ cells/ $/ \mathrm{cm}^{2}$. Twenty-four hours after plating, serum was removed and the cells were infected with recombinant adenoviruses at a multiplicity of infection (MOI) of 50.

Western blotting. The tissues were lysed in modified RIPA buffer or lysed directly in $1 \mathrm{X}$ sodium dodecyl sulfate (SDS) loading buffer. After the process of electrophoresis and transmembrane, proteins on the nitrocellulose membrane were probed with the TLR9, phosphatidylionositol 3 kinase (PI3K), protein kinase B (Akt), phosphorylated-Akt (1:500; Cell Signaling Technology, Danvers, MA, USA) and GAPDH (1:5,000; Bioworld Technology Inc., St. Louis Park, MN, USA) primary antibody followed by incubation with the secondary antibodies (1:5,000; Immunology Consultants Laboratory, Portland, OR, USA). The bands were visualized by enhanced chemiluminescence using ECL (Pierce Chemical) and captured on X-ray film. The total TLR9 or PI3K protein level was normalized to the GAPDH protein level, and the phosphorylated-Akt level was normalized to the Akt protein level.

Northern blot analysis. Total RNA (20 $\mu \mathrm{g})$, extracted using TRIzol reagent according to the manufacturer's instructions (Invitrogen), was separated on 1\% agarose gel with 3\% formaldehyde and 10\% 10X 4-morpholinepropanesulfonic acid. The
RNA was transferred to an uncharged nylon membrane and UV cross-linked. The membrane was prehybridized at $42^{\circ} \mathrm{C}$ for $2 \mathrm{~h}$ with $1 \mathrm{ml} / \mathrm{cm}^{2}$ QuikHyb Hybridization solution (Stratagene, La Jolla, CA, USA). DNA oligonucleotides, complementary to the mature microRNAs, were obtained from Integrated DNA Technologies (Coralville, IA, USA). The probes were 5 '-end labeled with Redivue adenosine $5^{1}-\left[\gamma^{-}{ }^{32} \mathrm{P}\right]$ triphosphate, triethylammonium salt (Amersham Biosciences) using a microRNA probe and marker kit (Ambion) and used for hybridization $\left(10^{5} / \mathrm{cm}^{2}\right)$. The blot was hybridized overnight and then washed with $2 \mathrm{X}$ sodium chloride sodium citrate buffer/0.1\% SDS and exposed to X-ray film. Blots were stripped using 0.5\% SDS and reprobed after prehybridization.

Cell proliferation assay. Cell proliferation was assessed by bromodeoxyuridine (BrdUrd) incorporation using a BrdUrd ELISA colorimetric assay (Roche). To determine the proliferation of $\mathrm{H} 460$ cells, the cells were initially plated at a density of $2 \times 10^{5} / 60 \mathrm{~mm}$ dish. After the cells had been incubated, they were counted using a hemocytometer (Neubauer, Horsham, Germany) and then plotted.

Cell migration assay. $\mathrm{H} 460$ cells $\left(10^{5}\right.$ cells/well $)$ were suspended in $0.5 \mathrm{ml}$ of $1 \%$ FBS MEM and placed in the top chamber of the well, while $0.750 \mathrm{ml}$ of $10 \%$ FBS MEM were added to the bottom compartment. Following a 48-h incubation, non-migrating cells were scraped from the membrane of the top compartment, and cells that had migrated through the membrane were fixed and stained using the Protocol Diff-Quik stain set (Siemens, Munich, Germany). The membranes were excised and mounted on a standard microscope slide (Curtin Matheson Scientific, Inc., Houston, TX, USA). The number of cells that migrated were determined from five random highpower fields (HPFs).

Chemicals. TLR9 ligand CpG-oligodeoxynucleotides (CpG-ODN) were purchased from InvivoGen (San Diego, CA, USA). Wortmannin (WM), the inhibitor of PI3K, was purchased from Calbiochem (San Diego, CA, USA). Triciribine hydrate (TCN), the inhibitor of Akt, was purchased from Sigma Chemical Co. (St. Louis, MO, USA). The chemicals were dissolved in phosphate-buffered saline (PBS). The dose of CpG was $5 \mu \mathrm{g} / \mathrm{ml}$, and the doses of WM and TCN were $25 \mu \mathrm{M}$.

Statistical analysis. Comparisons between two observations were assessed by the Student's paired t-test. One- or two-way ANOVA was used followed by the Bonferroni test for post hoc analysis when multiple comparisons were made. Data were expressed as the mean \pm standard error (SE). $\mathrm{P}<0.05$ was considered statistically significant.

\section{Results}

Expression of TLR9 in lung cancer tissue. The expression of TLR9 in lung cancer tissues obtained from lung cancer patients was increased compared with the controls (Fig. 1A).

Effects of TLR9 ligand on the tumor mass weight and size. TLR9 ligand CpG-ODN caused an increase in the mean tumor weight after 3 weeks compared with that treated with PBS. 
A
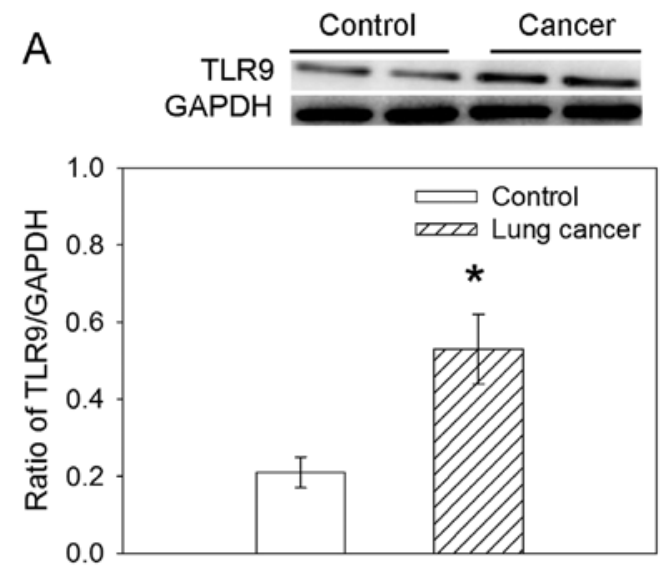

B

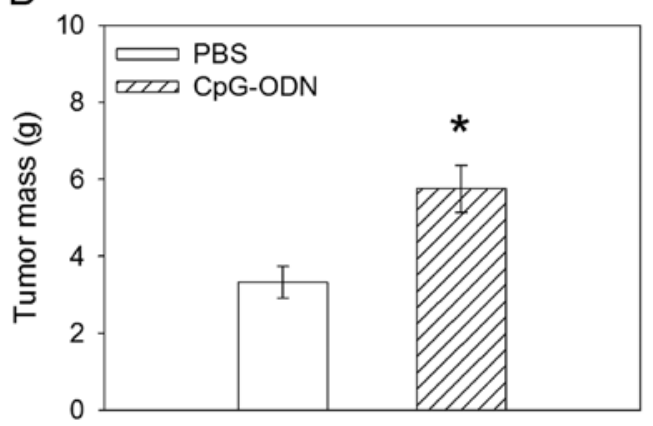

C

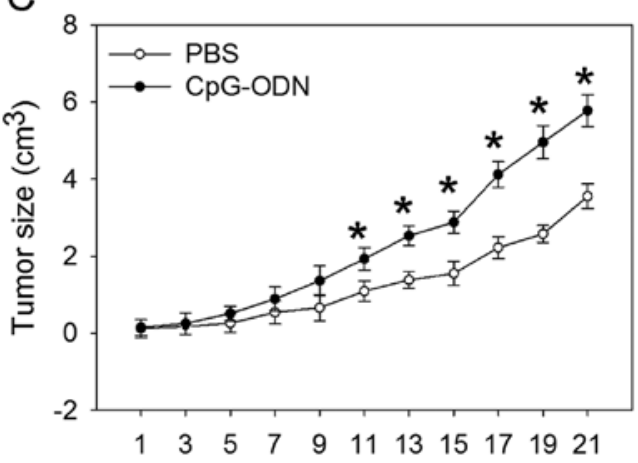

Figure 1. Toll-like receptor 9 (TLR9) expression and effects of TLR9 ligand on the tumor weight and size. (A) Expression of TLR9 in the lung cancer tissue. (B) Effects of phosphate-buffered saline (PBS) and TLR9 ligand $\mathrm{CpG}$ on the tumor mass weight (on day 21). (C) Effects of PBS and TLR9 ligand CpG-oligodeoxynucleotides (CpG-ODN) on the tumor size. The tumor weight was measured 3 weeks after treatment and the tumor size was measured every other day. Values are mean \pm standard error (SE). ${ }^{*} \mathrm{P}<0.05$ vs. PBS. $\mathrm{n}=6$ for each group.

The ligand of TLR9 CpG-ODN also increased the size of the tumor mass from 11 days after treatment (Fig. 1B and C).

Effects of TLR9 ligand on proliferation and migration. $\mathrm{H} 460$ cells treated with TLR9 ligand CpG-ODN promoted the proliferation as compared to that with PBS after $48 \mathrm{~h}$. In the Boyden chamber migration assays, CpG-ODN induced an increase in the migration of $\mathrm{H} 460$ human lung cancer cells (Fig. 2).

Expression of miR-26a. miR-26a expression was increased in the lung cancer tissues obtained from lung cancer patients
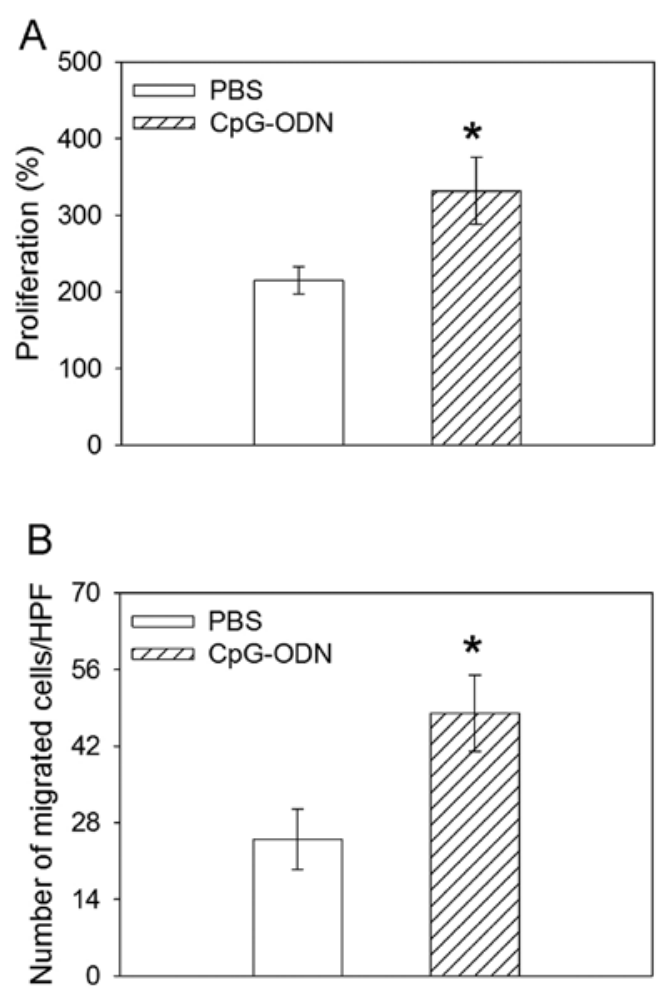

Figure 2. Effects of Toll-like receptor 9 (TLR9) ligand on proliferation and migration. (A) Effects of $\mathrm{H} 460$ cell treatment with phosphate-buffered saline (PBS), TLR9 ligand CpG-oligodeoxynucleotides (CpG-ODN) on proliferation. (B) Effects of H460 cell treatment with PBS and TLR9 ligand CpG-ODN on migration. Values are mean \pm standard error $(\mathrm{SE}) .{ }^{*} \mathrm{P}<0.05$ vs. $\mathrm{PBS} . \mathrm{n}=6$ for each group.

compared with the controls. In H460 cells, TLR9 ligand CpG-ODN induced an increase in the expression of miR-26a compared with PBS (Fig. 3).

Effects of miR-26a overexpression on the tumor in mice and H460 human lung cancer cell line. Northern blot analysis in $\mathrm{H} 460$ cells cultured in serum-free (SF) medium or infected at a MOI of 50 or 100 showed efficient overexpression of the mature miR-26a. The overexpression of miR-26a increased the tumor mass weight and size in the nude mice. The proliferation and migration were promoted after overexpression of miR-26a in the H460 human lung cancer cell line (Fig. 4).

Effects of miR-26a overexpression on the expression of PI3K and phosphorylated Akt. In the $\mathrm{H} 460$ human lung cancer cell line, the overexpression of miR-26a increased the expression of the PI3K protein level. The overexpression of miR-26a also significantly induced an increase in the level of phosphorylation of Akt in H460 cells (Fig. 5).

Effects of PI3K or Akt inhibitor on the proliferation and migration induced by miR-26a overexpression. The inhibitor of PI3K WM abolished the increase in the proliferation and migration induced by the overexpression of miR-26a in the human lung cancer cell line H460. TCN, the inhibitor of Akt, also abolished the increase in the proliferation and migration induced by the overexpression of miR-26a in H460 cells (Fig. 6). 
A
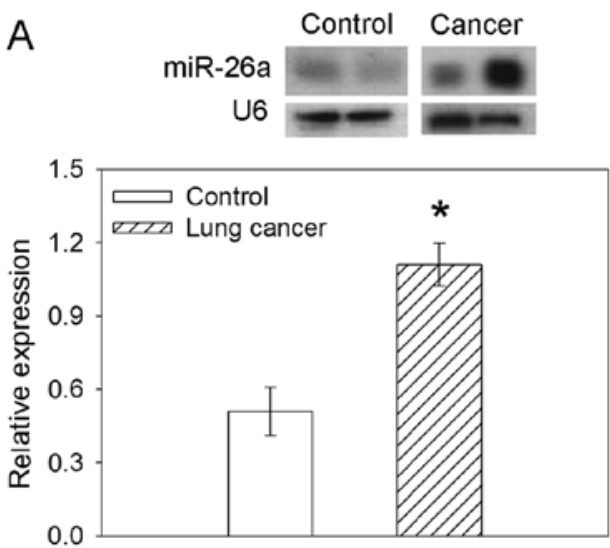

B

PBS CpG-ODN

miR-26a

U6

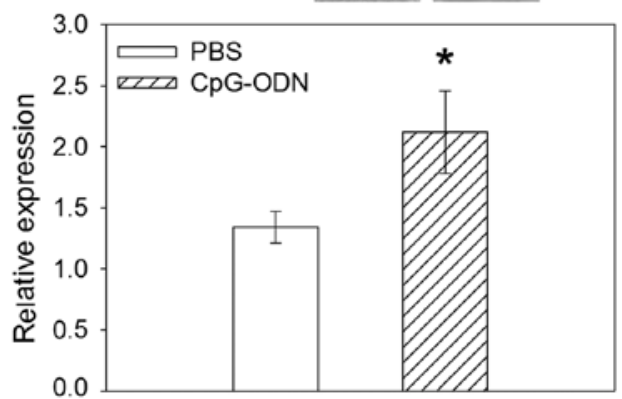

Figure 3. Expression of miR-26a. (A) Expression of miR-26a in lung cancer tissue. (B) Effects of Toll-like receptor 9 (TLR9) ligand CpG-oligodeoxynucleotides (CpG-ODN) on the expression of miR-26a in $\mathrm{H} 460$ cells. Values are mean \pm standard error (SE). ${ }^{*} \mathrm{P}<0.05$ vs. phosphate-buffered saline (PBS), $\mathrm{n}=6$ for each group.

A

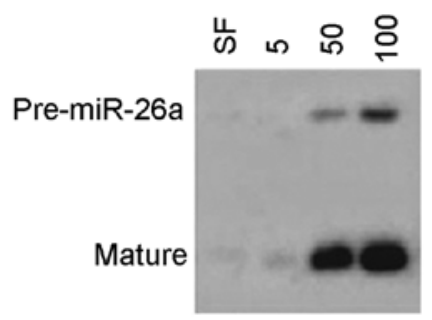

B
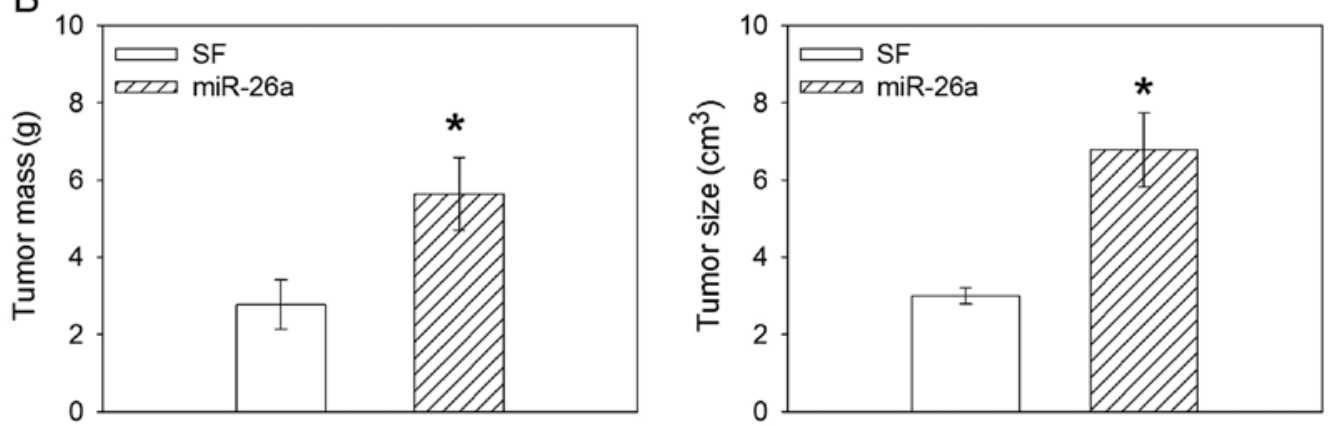

C
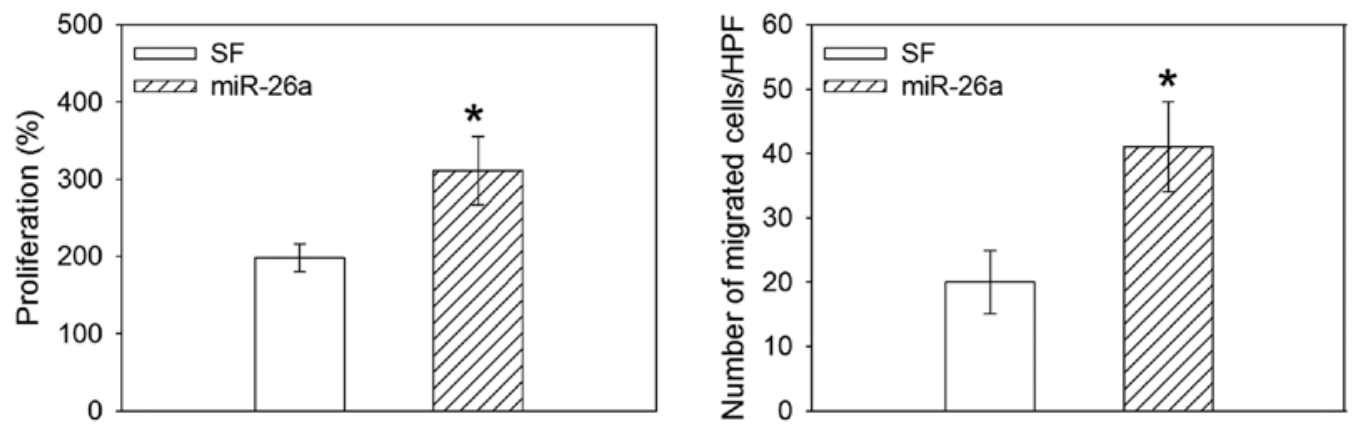

Figure 4. Effects of miR-26a overexpression on the tumor in mice and the H460 human lung cancer cell line. (A) H460 lung cancer cell line in serum-free (SF) medium was infected with adenoviruses expressing miR-26a at the indicated multiplicity of infection (MOI), and miR-26a was detected by Northern blot analysis on $20 \mu \mathrm{g}$ of RNA. (B) Effects of overexpression miR-26a on the tumor mass weight and size. (C) Effects of overexpression miR-26a on the proliferation and migration of human lung cell line H460. Values are mean \pm standard error (SE). ${ }^{*} \mathrm{P}<0.05$ vs. phosphate-buffered saline (PBS). $\mathrm{n}=6$ for each group.

\section{Discussion}

TLRs are widely expressed on various tumor cells, including lung cancer cells $(7,20)$. TLR agonist alters the biological character of lung cancer cells, promoting proliferation and enhancing the metastatic potential of tumor cells in vitro and in vivo $(21,22)$. miRNAs are differentially expressed in various types of cancer and play important roles in cancer progres- 
A
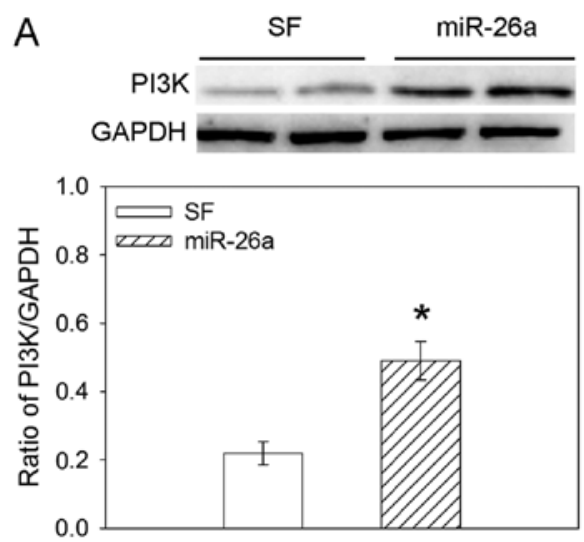

B
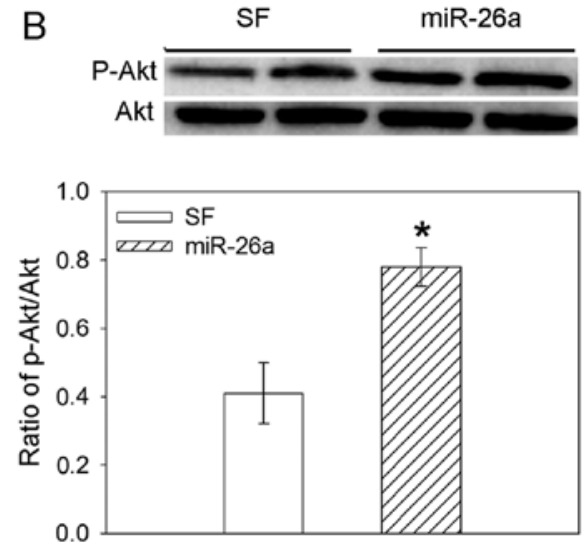

Figure 5. Effects of miR-26a overexpression on the expression of phosphatidylionositol 3 kinase (PI3K) and phosphorylated-protein kinase B (Akt). (A) Effects of miR-26a overexpression on the expression of PI3K. (B) Effects of miR-26a overexpression on the expression of phosphorylated-Akt. Values are mean \pm standard error (SE). ${ }^{*} \mathrm{P}<0.05$ vs. phosphate-buffered saline (PBS), $\mathrm{n}=6$ for each group.
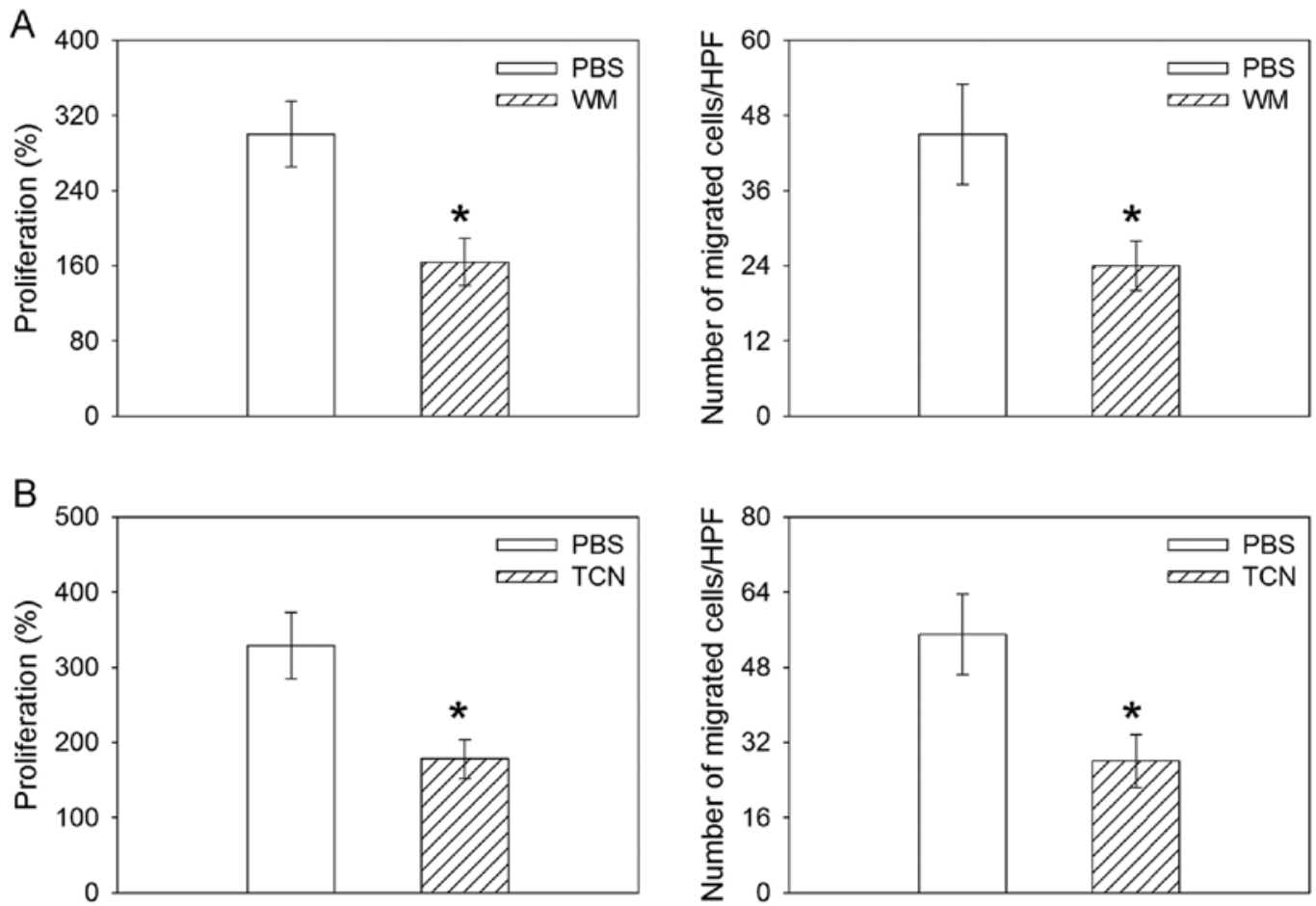

Figure 6. Effects of phosphatidylionositol 3 kinase (PI3K) inhibitor or protein kinase B (Akt) inhibitor on the proliferation and migration induced by miR-26a overexpression in the human lung cancer cell line. (A) Effects of PI3K inhibitor wortmannin (WM) on the proliferation and migration induced by miR-26a overexpression in the $\mathrm{H} 460$ human lung cancer cell line. (B) Effects of Akt inhibitor triciribine hydrate (TCN) on the proliferation and migration induced by miR-26a overexpression in the $\mathrm{H} 460$ human lung cancer cell line. Values are mean \pm standard error (SE). ${ }^{*} \mathrm{P}<0.05$ vs. phosphate-buffered saline (PBS), $\mathrm{n}=6$ for each group.

sion (23). Additionally, they are putative markers for improving cancer classification, diagnosis and clinical prognostic information $(24,25)$. Accumulating evidence have demonstrated that miRNAs are involved in regulating the biological effects of TLR on various cells $(26,27)$. In the present study, we have demonstrated that miR-26a is involved in the TLR9-mediated growth and migration of lung cancer through the PI3K-Akt signaling pathway.

TLRs pathways are key regulators in cancer progression as well as chemoresistance. TLRs serve as cell surface sensors that can initiate pathways leading to proliferation and chemoresistance; as well as mediators that are able to regulate the infiltrating immune cells to provide further support for cancer progression (28). In the present study, TLR9 ligand CpG-ODN caused an increase in the weight and the size of tumor mass in the nude mice, and promoted the proliferation and migration of H460 human lung cancer cells. In addition, the expression of TLR9 in lung cancer tissues obtained from lung cancer patients was increased. These results indicate that the activation of TLR9 in lung cancer cells contributed to the growth and metastasis of tumor cells and is involved in tumor progression, which is supported by the previous finding that 
TLR9 agonist CpG-ODN promotes the growth and metastatic potential of human lung cancer cells (29).

It has been shown that miRNAs play critical roles in regulating the biological effects of TLRs signaling pathways on various types of cells $(26,30)$. miR-26a promotes glioma progression in vitro and in vivo and is associated with glioma development (17). Human cholangiocarcinoma tissues and cell lines had increased levels of miR-26a compared with the non-cancerous biliary epithelial cells, and miR-26a promotes growth of cholangiocarcinoma (18). In the present study, we show that the expression of miR-26a was increased in the lung cancer tissues obtained from lung cancer patients, and TLR9 ligand $\mathrm{CpG}-\mathrm{ODN}$ induced an increase in miR-26a expression in H460 human lung cancer cells. Furthermore, miR-26a overexpression increased the weight and size of the tumor mass in the nude mice, and promoted the proliferation and migration in the human lung cancer cell line H460. These results indicated that miR-26a contributes to the growth and metastasis of tumor cells and is involved in the TLR9-mediated growth and migration of lung cancer.

It is well known that the PI3K/Akt pathway plays a critical role in tumor biology (31). TLR9 agonist may promote the metastasis of human lung cancer cells via CXCR4/SDF-1/Akt pathway (29). However, whether miR-26a regulated the growth and migration of lung cancer through the PI3K/Akt pathway is not understood. In the present study, we show that miR-26a overexpression increased the expression of PI3K protein level and phosphorylation of the Akt level in the H460 human lung cancer line. The inhibitor of PI3K WM or inhibitor of Akt TCN abolished the increase in the proliferation and migration induced by the overexpression of miR-26a in the H460 human lung cancer cell line. These results demonstrate that miR-26a mediates the growth and migration of lung cancer through the PI3K-Akt signaling pathway.

In conclusion, TLR9 promoted the growth and migration of lung cancer and miR-26a is involved in the TLR9-mediated growth and migration of lung cancer through the PI3K-Akt signaling pathway.

\section{References}

1. Gosu V, Basith S, Kwon OP and Choi S: Therapeutic applications of nucleic acids and their analogues in Toll-like receptor signaling. Molecules 17: 13503-13529, 2012.

2. Takagi M: Toll-like receptor - a potent driving force behind rheumatoid arthritis. J Clin Exp Hematop 51: 77-92, 2011.

3. Chang YJ, Wu MS, Lin JT and Chen CC: Helicobacter pyloriInduced invasion and angiogenesis of gastric cells is mediated by cyclooxygenase-2 induction through TLR2/TLR9 and promoter regulation. J Immunol 175: 8242-8252, 2005.

4. Eiró N1, Altadill A, Juárez LM, et al: Toll-like receptors 3, 4 and 9 in hepatocellular carcinoma: Relationship with clinicopathological characteristics and prognosis. Hepatol Res: Jun 6, 2013 (Epub ahead of print).

5. Zhang L, Qin H, Guan X, Zhang K and Liu Z: The TLR9 gene polymorphisms and the risk of cancer: evidence from a metaanalysis. PLoS One 8: e71785, 2013.

6. Sorrentino R, Morello S, Giordano MG, et al: CpG-ODN increases the release of VEGF in a mouse model of lung carcinoma. Int J Cancer 128: 2815-2822, 2011.

7. Droemann D, Albrecht D, Gerdes J, et al: Human lung cancer cells express functionally active Toll-like receptor 9 . Respir Res 6: 1,2005 .
8. Belmont L, Rabbe N, Antoine M, et al: Expression of TLR9 in tumor-infiltrating mononuclear cells enhances angiogenesis and is associated with a worse survival in lung cancer. Int $\mathbf{J}$ Cancer 134: 765-777, 2014.

9. Ren T, Wen ZK, Liu ZM, Liang YJ, Guo ZL and Xu L: Functional expression of TLR9 is associated to the metastatic potential of human lung cancer cell: functional active role of TLR9 on tumor metastasis. Cancer Biol Ther 6: 1704-1709, 2007.

10. Bartel DP: MicroRNAs: genomics, biogenesis, mechanism, and function. Cell 116: 281-297, 2004.

11. Lee RC, Feinbaum RL and Ambros V: The C. elegans heterochronic gene lin-4 encodes small RNAs with antisense complementarity to lin-14. Cell 75: 843-854, 1993.

12. Cuellar TL and McManus MT: MicroRNAs and endocrine biology. J Endocrinol 187: 327-332, 2005.

13. Krol J, Loedige I and Filipowicz W: The widespread regulation of microRNA biogenesis, function and decay. Nat Rev Genet 11: 597-610, 2010.

14. Miller AM, Gilchrist DS, Nijjar J, et al: MiR-155 has a protective role in the development of non-alcoholic hepatosteatosis in mice. PLoS One 8: e72324, 2013.

15. Ma Y, Bao-Han W, Lv X, et al: MicroRNA-34a mediates the autocrine signaling of PAR2-activating proteinase and its role in colonic cancer cell proliferation. PLoS One 8: e72383, 2013.

16. Yang X, Du WW, Li H, et al: Both mature miR-17-5p and passenger strand miR-17-3p target TIMP3 and induce prostate tumor growth and invasion. Nucleic Acids Res 41: 9688-9704, 2013.

17. Qian X, Zhao P, Li W, et al: MicroRNA-26a promotes tumor growth and angiogenesis in glioma by directly targeting prohibitin. CNS Neurosci Ther 19: 804-812, 2013.

18. Zhang J, Han C and Wu T: MicroRNA-26a promotes cholangiocarcinoma growth by activating $\beta$-catenin. Gastroenterology 143 : 246-256 e248, 2012.

19. Savry A, Carre M, Berges R, et al: Bcl-2-enhanced efficacy of microtubule-targeting chemotherapy through Bim overexpression: implications for cancer treatment. Neoplasia 15: 49-60, 2013.

20. Bhattacharya D and Yusuf N: Expression of Toll-like receptors on breast tumors: taking a toll on tumor microenvironment. Int J Breast Cancer 2012: 716564, 2012.

21. He W, Liu Q, Wang L, Chen W, Li N and Cao X: TLR4 signaling promotes immune escape of human lung cancer cells by inducing immunosuppressive cytokines and apoptosis resistance. Mol Immunol 44: 2850-2859, 2007.

22. Min R, Zun Z, Siyi L, et al: Increased expression of Toll-like receptor-9 has close relation with tumour cell proliferation in oral squamous cell carcinoma. Arch Oral Biol 56: 877-884, 2011.

23. Esquela-Kerscher A and Slack FJ: Oncomirs - microRNAs with a role in cancer. Nat Rev Cancer 6: 259-269, 2006.

24. Majumder S and Jacob ST: Emerging role of microRNAs in drug-resistant breast cancer. Gene Expr 15: 141-151, 2011.

25. Minguez B and Lachenmayer A: Diagnostic and prognostic molecular markers in hepatocellular carcinoma. Dis Markers 31: 181-190, 2011.

26. Chen R, Alvero AB, Silasi DA, et al: Regulation of IKKbeta by miR-199a affects NF-kappaB activity in ovarian cancer cells. Oncogene 27: 4712-4723, 2008.

27. Wendlandt EB, Graff JW, Gioannini TL, McCaffrey AP and Wilson ME: The role of microRNAs miR-200b and miR-200c in TLR4 signaling and NF- $\kappa \mathrm{B}$ activation. Innate Immun 18: 846-855, 2012.

28. Chen R, Alvero AB, Silasi DA, Steffensen KD and Mor G: Cancers take their Toll - the function and regulation of Toll-like receptors in cancer cells. Oncogene 27: 225-233, 2008.

29. Xu L, Zhou Y, Liu Q, et al: CXCR4/SDF-1 pathway is crucial for TLR9 agonist enhanced metastasis of human lung cancer cell. Biochem Biophys Res Commun 382: 571-576, 2009.

30. Tserel L, Runnel T, Kisand K, et al: MicroRNA expression profiles of human blood monocyte-derived dendritic cells and macrophages reveal miR-511 as putative positive regulator of Toll-like receptor 4. J Biol Chem 286: 26487-26495, 2011.

31. Chen X, Zhou JY, Zhao J, Chen JJ, Ma SN and Zhou JY: Crizotinib overcomes hepatocyte growth factor-mediated resistance to gefitinib in EGFR-mutant non-small-cell lung cancer cells. Anticancer Drugs 24: 1039-1046, 2013. 